\title{
Hybrid Renewable Energy Resources Management for Optimal Energy Operation in Nano-Grid
}

\author{
Faiza Qayyum ${ }^{1}$, Faisal Jamil ${ }^{1}$, Shabir Ahmad ${ }^{2}$ and Do-Hyeun Kim ${ }^{1, *}$ \\ ${ }^{1}$ Department of Computer Engineering, Jeju National University, Jeju-si, Jeju Special Self-Governing Province, 63243, \\ Korea \\ ${ }^{2}$ Department of IT Convergence Engineering, Gachon University, Sujeong-Gu, Seongnam-Si, Gyeonggi-Do, 461-701, Korea \\ *Corresponding Author: Do-Hyeun Kim. Email: kimdh@jejunu.ac.kr \\ Received: 30 April 2021; Accepted: 05 July 2021
}

\begin{abstract}
Renewable energy resources are deemed a potential energy production source due to their cost efficiency and harmless reaction to the environment, unlike non-renewable energy resources. However, they often fail to meet energy requirements in unfavorable weather conditions. The concept of Hybrid renewable energy resources addresses this issue by integrating both renewable and non-renewable energy resources to meet the required energy load. In this paper, an intelligent cost optimization algorithm is proposed to maximize the use of renewable energy resources and minimum utilization of non-renewable energy resources to meet the energy requirement for a nanogrid infrastructure. An actual data set comprising information about the load and demand of utility grids is used to evaluate the performance of the proposed nanogrid energy management system. The objective function is formulated to manage the nanogrid operation and implemented using a variant of Particle Swarm Optimization (PSO) named recurrent PSO (rPSO). Firstly, rPSO algorithm minimizes the installation cost for nanogrid. Thereafter, the proposed NEMS ensures cost efficiency for the post-installation period by providing a daily operational plan and optimizing renewable resources. State-of-the-art optimization models, including Genetic Algorithm (GA), bat and different Mathematical Programming Language (AMPL) solvers, are used to evaluate the model. The study's outcomes suggest that the proposed work significantly reduces the use of diesel generators and fosters the use of renewable energy resources and beneficiates the eco-friendly environment.
\end{abstract}

Keywords: Smart grid; nanogrid; distributed generation (DG); renewable energy; optimization; machine learning

\section{Introduction}

Most of the central power generators rely upon conventional means of energy to produce electricity. These resources encompass oil, natural gas, coal, and nuclear energy, collectively termed fossil-fuel-based solutions that generate around $80 \%$ of the world's energy [1]. These non-renewable energy resources pollute about 30.8 billion tons of $\mathrm{CO}_{2}$ in the environment every year, becoming

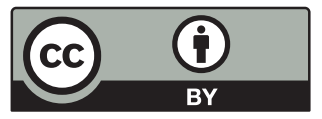

This work is licensed under a Creative Commons Attribution 4.0 International License, which permits unrestricted use, distribution, and reproduction in any medium, provided the original work is properly cited. 
a significant threat to environmental pollution [2]. On the other hand, natural resources such as solar, wind, and hydrothermal hold a great potential to meet ever-increasing electricity requirements without harming the environment. However, due to their high dependence upon weather stochasticity, these renewable energy resources often fail to produce an adequate amount of energy $[3,4]$. In such a scenario, an ideal solution is formed by integrating renewable and nonrenewable energy resources to exploit their collective capacities, known as hybrid renewable energy source (HRES) [5]. HRES is a combination of different diesel generators used to meet the required load [1].

Since past several years, distributed generation (DG) has gained popularity because of its ability to mitigate the need of grid extendibility [6-8]. Although DG is considered as one of the best possible sources to generate on-site energy; however, it suffers from issues like installation cost and instant power provision [8]. Controlled systems in the form of a microgrid or nanogrid were introduced to overcome the said issue. These systems hold enough capacity to generate electricity to meet energy demands of a limited geographical area [9]. A nanogrid is deemed an integral aspect of DG wherein electricity is generated for a single building [9]. In other words, it is a confined electricity supply system that can serve a limited geographical area either being isolated or connected to the main power grid via gateway [10]. The scientific community has presented various nanogrid structure-based optimization solutions in the form of analytical methods for sizing photovoltaic for nanogrid with the objective of increased reliability and least loss of power supply [11-13].

Similarly, the authors suggested Mixed integer linear programming (MILP) to reduce cost for optimal sizing of DG unit and battery [14]. Photovoltaic (PV) solar energy is generated by transforming sunlight into electricity using a technology based on the photoelectric effect. Recently, PVs systems are used to generate energy because they have minimum investment cost, feasible integration onto the buildings (i.e., rooftop), and efficient performance. Integrating PVs with fuel-based sources along with energy storage unit forms a hybrid renewable energy system (HRES), which has been proven quite useful in fulfilling the desired outcomes about reduced energy cost and $\mathrm{CO}_{2}$ emission $[10,15,16]$.

However, very few attempts have been made to exploit the collective potential of renewable and non-renewable energy resources for nanogrid infrastructures to the best of our knowledge. In this study, we present an intelligent nanogrid energy management system that interlinks different components of renewable and non-renewable energy resources to meet household energy demand. We believe that a well-designed nanogrid structure should have maximum utilization of renewables, minimum utilization of non-renewables, and least cost inclusive of installation, maintenance, and operation. However, most of the contemporary state-of-the-art focuses on reducing the static cost of nanogrid installation and overlooks post-installation factors like daily maintenance and operational plan. Considering these factors while designing nanogrid structures has a high probability of significantly reducing cost for efficient energy management systems. This study presents a novel nanogrid Energy Management System (NEMS) that provides an optimal solution using recursive particle swarm optimization (PSO). A novel objective function is designed for optimization, which maximizes the use of renewable energy resource (i.e., PV) and introduces a strategy for energy management plan to effectuate the overall nanogrid structure optimally. The proposed objective function is implemented using a variant of PSO termed recursive particle swarm optimization (rPSO). The performance of the system is evaluated using a Genetic Algorithm, BAT and AMPL solvers. The rPSO results in minimum cost, including installation, maintenance, and operational cost. 


\section{State-of-the-art Approaches}

In recent years, smart grid-based technologies have played an immense role in power distribution across globe. Their prime concern is to decrease the load from the main power grid and foster distributed generation (DG) to meet ever-increasing energy demands. Owing to the ability to meet the energy demands of a single building without requiring power from the main grid, nanogrid based power distribution structures have been receiving increased popularity in recent years. Nanogrid enriches the concept of DG by providing electricity to a limited geographical area (i.e., house) in a controlled manner. Broadly, the scientific community has addressed nanogrid related issues in two dimensions: (1) Nanogrid control or hardware optimization and (2) Nano-grid's cost optimization.

Nanogrid control is a crucial part of nanogrid structure because it acts as the brain of the systems. It is implemented by a nanogrid controller and ensures flexible coordination among interlinked sources for optimal power production and consumption. The controller tracks the records of power in two categories: (1) Supply-side management (SSM) and (2) demand-side management (DSM). The SSM is about the sources where energy is received, for instance, grid, wind turbines (WT) and photovoltaic modules, etc. The DSM refers to the load appliances such as fan, oven, refrigerator, heater, etc. The behavior of both the categories fluctuates dynamically, and their optimization has been the major concern of the scientific community. In the study [17], an ad-hoc nano-grid has been implemented to meet the demands of the required load by transmitting power through optimal paths. This technique deals explicitly with the scenarios wherein nanogrid has no connectivity to the national grid. The proposed system enables a single load to wirelessly connect with all the other nodes in the network to transmit power from the source to load. The nodes in a network select the required path via control algorithm. The nodes improve the power flow by choosing the transmission path having least cost. A cost function control technique is presented in [18]. Main purpose of the technique is to decrease the payback time for a nano-grid purchased by a consumer. This technique deals with DSM and utilizes central control to capture nanogrid's hardware, two-way communication, smart grid, and internet connection to implement a rule-based control algorithm. The algorithm reduces the loads in response to the fluctuations in prices of the national power grid. It decides to sell or use photovoltaic production according to buy-back price of the main grid. The algorithm suggests an optimal plan for three modes: (1) automatic response, (2) load curtailment and (3) islanding mode depending on the energy at hand, weather condition, and grid's buying price.

In the study [19], DSM based algorithm has been implemented to schedule the charge time of plug-in electric vehicle (PEV) according to power demand in a prior day. This refrains the battery to be charged during peak power consumption time. The technique results in cost optimization by flattening the consumption curve for nanogrid, as also stated in [20]. Least Slack First (LSF) algorithm has been presented by [21]. The LSF schedules the power supply to interactive loads and background loads. The converters manipulate voltages in nanogrid to meet the load requirements. It enables interaction among sources of nanogrid and system bus [22]. Typically, DC to DC, AC to DC and DC to AC converters are used in nanogrids [23]. Dual-active-bridge based bidirectional micro-inverter has been presented in [24]. This converter uses Lithium-Ion Ultra-Capacitors (LICs) to enhance power capacity of nanogrid by receding photovoltaic modules factor, which saves the cost of diesel generators.

Similarly, Boost-derived hybrid converter has been proposed by [25] wherein single-phase bi-directional bridge network is used instead of a control switch. It manages the operating of nanogrid with both AC and DC loads by simultaneously producing AC and DC output. Similarly, 
various efforts have been made for nanogrid's converter [26]. Ban et al. [12] proposed optimal sizing and cyber-physical Energy Management system for nanogrids to reduce cost and increase reliability. Strnad et al. [13], and Akram et al. [14] suggested Mixed integer linear programming (MILP) to reduce cost for optimal sizing of DG unit and battery. Ayop et al. [11] introduced an analytical method for sizing of photovoltaic for nanogrid with the objective of increased reliability and least loss of power supply.

The majority of the aforementioned state-of-the-art about nanogrid focuses on optimizing hardware components of nanogrid or its installation cost. However, we argue that various other factors must also be contemplated while designing nanogrid. For example, a plethora of literature focuses on reducing static cost at the time of installation; however, some crucial aspects that occur post-installation must also be considered like daily operational and maintenance plans. The study [27] presents virtual energy storage (VES)-DSM system that ensures power supply in a nanogrid infrastructure. The VES converts thermal inertia loads into electrochemical batteries such as appliances like refrigerators and air-conditioners. VES follows a priority-based algorithm that controls appliances for energy management.

Another study [28] presents an energy cost reduction model for PV-based nano-grid connected to the power grid. The model uses three configurations of the nano-grid model that are optimized via nested integer linear programming. In addition, real-time energy consumption load is considered to meet energy demands via implementing fitness functions.

\section{System Overview}

This section encompasses details about the flow of methodology proposed to minimize the nanogrid cost and optimal plan for daily operations to have maximum utilization of renewable energy resources (i.e., solar) and least utilization of non-renewable energy resources (i.e., diesel generator). The data set contains information about solar radiation and load demand of appliances of a house in Pakistan. Since the data set includes missing values that may cause skewness, the data set has been pre-processed and normalized to handle the said issues. Thereafter, the data values are given to the optimizer, which reports optimal parameters following some constraints. An objective function is formed to decide the optimality of the parameters. The optimizer takes solar radiation and load data as an input and produces two optimal parameters $(\mathrm{m} 0$ and $\mathrm{m} 0)$ for battery operation. These parameters and solar radiation and load demand are given as input to the optimizer to compute the optimal cost for installing, operating, and maintaining the nanogrid. Finally, the NEMS algorithm suggests a daily plan to operate nano-grid to ensure maximum use of renewable energy resources (solar radiation) and minimum use of non-renewable energy resources, as shown in Fig. 1.

\subsection{Objective Function}

The objective function is formed to serve two main concerns: (1) reduce total cost for nanogrid and (2) suppression of renewable energy resources. The designed multi-objective optimization solution focuses on minimizing the said two concerns while meeting the load demands of a residential building (i.e., house) in Pakistan. This section presents the objective function and the proposed NEMS algorithm, which gives a daily operational plan for nano-grids. Tab. 1 illustrates an explanation of the terms and acronyms used in the objective function. 


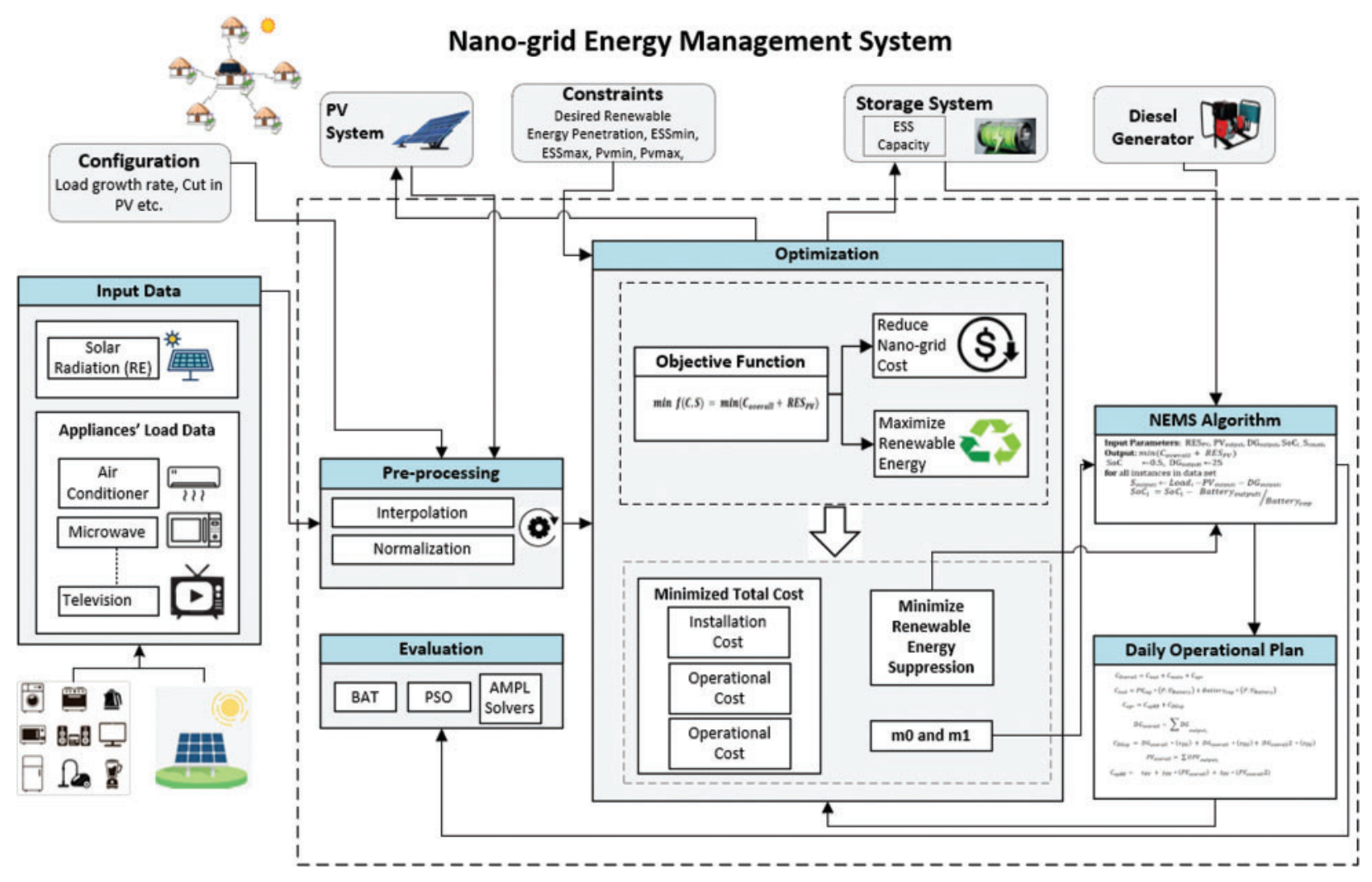

Figure 1: Proposed architecture diagram of optimized nano-grid energy provision solution

A formal description of the designed objective function is given below. The main goal of the objective function is to minimize the nano-grid's installation, maintenance and operational cost and suppression of renewable energy resources (i.e., WT and PV), as shown in Eq. (1).

$\min f(\boldsymbol{C}, \boldsymbol{S})=\min \left(\boldsymbol{C}_{\text {overall }}+\boldsymbol{R} E \boldsymbol{S}_{\boldsymbol{P} V}\right)$

The following equation computes overall cost that includes installation cost, maintenance cost and operational cost. These three costs are calculated at individual levels containing their modules involving components like photovoltaic, battery etc.

$C_{\text {Overall }}=C_{\text {inst }}+C_{\text {main }}+C_{\text {opr }}$

The installation cost is computed using Eq. (3). It includes the overall capacity of photovoltaic that integrates with per unit cost of the battery and total storage system (i.e., battery) capacity in combination with Per unit cost of the battery is computed. Finally, these computed costs are combined to calculate the overall installation cost.

$C_{\text {inst }}=P V_{\text {cap }} *\left(P . U_{\text {Battery }}\right)+$ Battery $_{\text {cap }} *\left(P . U_{\text {Battery }}\right)$

Similarly, operational cost is computed using Eq. (4). The operational cost combines operational cost of renewable energy and operational cost of diesel generator, as shown in the equation. 
Table 1: Description of acronyms used in the proposed objective function

\begin{tabular}{|c|c|c|c|}
\hline Symbol & Description & Symbol & Description \\
\hline $\mathrm{C}$ & Cost & $\mathbf{S}$ & Suppression \\
\hline $\mathrm{RES}_{\mathrm{PV}}$ & $\begin{array}{l}\text { Suppression of } \\
\text { renewable energy } \\
\text { resource (i.e., PV) }\end{array}$ & $x_{D G}, y_{D G}, z_{D G}$ & $\begin{array}{l}\text { Manufacturing constant } \\
\text { for diesel generator }\end{array}$ \\
\hline$C_{\text {overall }}$ & $\begin{array}{l}\text { Total cost, inclusive cost } \\
\text { of all both the resources } \\
\text { (i.e., renewable and } \\
\text { non-renewable) }\end{array}$ & $x_{P V}, y_{P V}, z_{P V}$ & $\begin{array}{l}\text { Manufacturing constant } \\
\text { for photovoltaics }\end{array}$ \\
\hline$C_{\text {inst }}$ & $\begin{array}{l}\text { Nanogrid's installation } \\
\text { cost }\end{array}$ & $\mathrm{PV}_{\mathrm{MnO}}$ & $\begin{array}{l}\text { Management and } \\
\text { operational cost of } \\
\text { photovoltaics (in per } \\
\text { unit) }\end{array}$ \\
\hline$C_{o p r}$ & $\begin{array}{l}\text { Nanogrid's operational } \\
\text { cost }\end{array}$ & $\mathrm{DG}_{\mathrm{MnO}}$ & $\begin{array}{l}\text { Management and } \\
\text { operational cost of } \\
\text { diesel generator (in per } \\
\text { unit) }\end{array}$ \\
\hline $\boldsymbol{C}_{\text {main }}$ & $\begin{array}{l}\text { Nanogrid's maintenance } \\
\text { cost }\end{array}$ & Battery $_{\mathrm{MnO}}$ & $\begin{array}{l}\text { Management and } \\
\text { operational cost of } \\
\text { energy storage system } \\
\text { (in per unit) }\end{array}$ \\
\hline $\mathbf{P V} \mathbf{C A P}_{\mathrm{CAP}}$ & $\begin{array}{l}\text { Photovoltaics' total } \\
\text { capacity }\end{array}$ & $\mathbf{P}_{\text {attained }}(\mathrm{RE})$ & $\begin{array}{l}\text { Attained value of } \\
\text { renewable energy } \\
\text { penetration }\end{array}$ \\
\hline Battery $_{c a p}$ & $\begin{array}{l}\text { Total storage system } \\
\text { (i.e., Battery) capacity }\end{array}$ & $\mathbf{P}_{\text {required }}(\mathrm{RE})$ & $\begin{array}{l}\text { Required value of } \\
\text { renewable energy } \\
\text { penetration }\end{array}$ \\
\hline P.U $U_{P V}$ & $\begin{array}{l}\text { Photovoltaics' per unit } \\
\text { cost }\end{array}$ & $\beta$ & $\begin{array}{l}\text { Decides range for } \\
\text { renewable energy } \\
\text { penetration }\end{array}$ \\
\hline P.U Battery & Per unit cost of battery & $m 0, m 1$ & $\begin{array}{l}\text { Two intermediate } \\
\text { parameters produced by } \\
\text { level } 1 \text { optimizer }\end{array}$ \\
\hline$C D G_{\mathrm{op}}$ & $\begin{array}{l}\text { Operational cost of } \\
\text { diesel generator }\end{array}$ & $\boldsymbol{P} \boldsymbol{V}_{\text {overall }}$ & $\begin{array}{l}\text { Total cost of } \\
\text { photovoltaics }\end{array}$ \\
\hline$C_{\mathrm{opRE}}$ & $\begin{array}{l}\text { Operational cost of } \\
\text { renewable energy }\end{array}$ & SoC & Battery's state-of-charge \\
\hline$D G_{\text {overall }}$ & $\begin{array}{l}\text { Total cost of diesel } \\
\text { generator }\end{array}$ & $D_{G_{\text {output }}}$ & $\begin{array}{l}\text { Output cost of diesel } \\
\text { generator }\end{array}$ \\
\hline
\end{tabular}


$C_{o p r}=C_{o p R E}+C_{D G o p}$

The total cost of the diesel generator is calculated using Eq. (5). It adds all the outputs produced by the diesel generators.

$D G_{\text {overall }}=\sum D G_{\text {output }_{i}}$

The operational cost of the diesel generator is computed using Eq. (6). It incorporates overall cost from three different aspects. First, the total cost of diesel generator is integrated with three manufacturing constraints for diesel generators, which is then added to compute the operational cost.

$C_{D G o p}=D G_{\text {overall }} *\left(x_{D G}\right)+D G_{\text {overall }} *\left(y_{D G}\right)+D G_{\text {overall }} 2 *\left(z_{D G}\right)$

The overall cost of photovoltaic (PV) renewable energy is computed using Eq. (7). It incorporates the sum of all outputs of photovoltaics (PV).

$P V_{\text {overall }}=\sum U P V_{\text {output }_{i}}$

The overall operational cost of renewable energy is shown in Fig. 8. It combines all the three manufacturing constants for photovoltaics to calculate the combined cost of renewable energy resources.

$C_{o p R E}=x_{P V}+y_{P V} *\left(P V_{\text {overall }}\right)+z_{P V} *\left(P V_{\text {overall }} 2\right)$

Similarly, the operational cost of distributed generation (DG) is calculated using Eq. (9). Again, it focuses on finding maximum DG output.

$D G_{\text {cap }}=\max \left(D G_{\text {output }_{i}}\right)$

The maintenance cost is computed using Eq. (10). It accumulates photovoltaic capacity, management and operational cost of photovoltaic, battery capacity, management and operating cost of battery, DG capacity and management and operational cost of diesel per unit. It has some constraints that ensure renewable energy penetration must lie within the range.

$$
\begin{aligned}
C_{\text {main }}= & P V_{\text {cap }} *\left(P V_{M n O}\right) \\
& + \text { Battery }_{\text {cap }} *\left(\text { Battery }_{M n O}\right)+D G_{\text {cap }} *\left(D G_{M n O}\right) \varepsilon P_{\text {attained }}(R E)\left[P_{\text {desired }}(R E)\right. \\
& \left.\left.+\beta, P_{\text {required }}(R E)-\beta\right)\right]
\end{aligned}
$$

\subsection{Nanogrid Energy Management System}

The algorithm of the proposed Nanogrid energy management system (NEMS) is illustrated in Algorithm 1. The proposed NEMS takes load value, storage capacity, solar radiation, mo and $\mathrm{m} 1$ as input. As a kick-off, state-of-charge (SoC) and diesel generator (DG) is initialized to 0.5 and 25 respectively. Thereafter, output of energy storage is computed for all the data instances by subtracting the output of photovoltaics, diesel generator from the required load. Then value for $\mathrm{SoC}$ is computed by dividing the obtained value of energy storage. If $\mathrm{SoC}$ is more than 0.9 then storage is considered as overcharged, and minimum output for diesel generator is reduced to 20 and value of suppression count is reduced by a single unit. If SoC lies between 0.8 to 0.9 or 
between $\mathrm{m} 1$ or 0.8 , then battery is deemed to be sufficiently charged, and DG remains same as 20 . If $\mathrm{SoC}$ is between $\mathrm{m} 0$ and $\mathrm{m} 1$, then battery is not charged and requires power of diesel generator to be charged. If SoC is less than 0.1 then battery is empty, and power of diesel generator is increased to 30 . If none of the condition is met, then algorithm will return suppression energy. On the other hand, if SoC is more than 1 or less than 0 then this is considered as an exception.

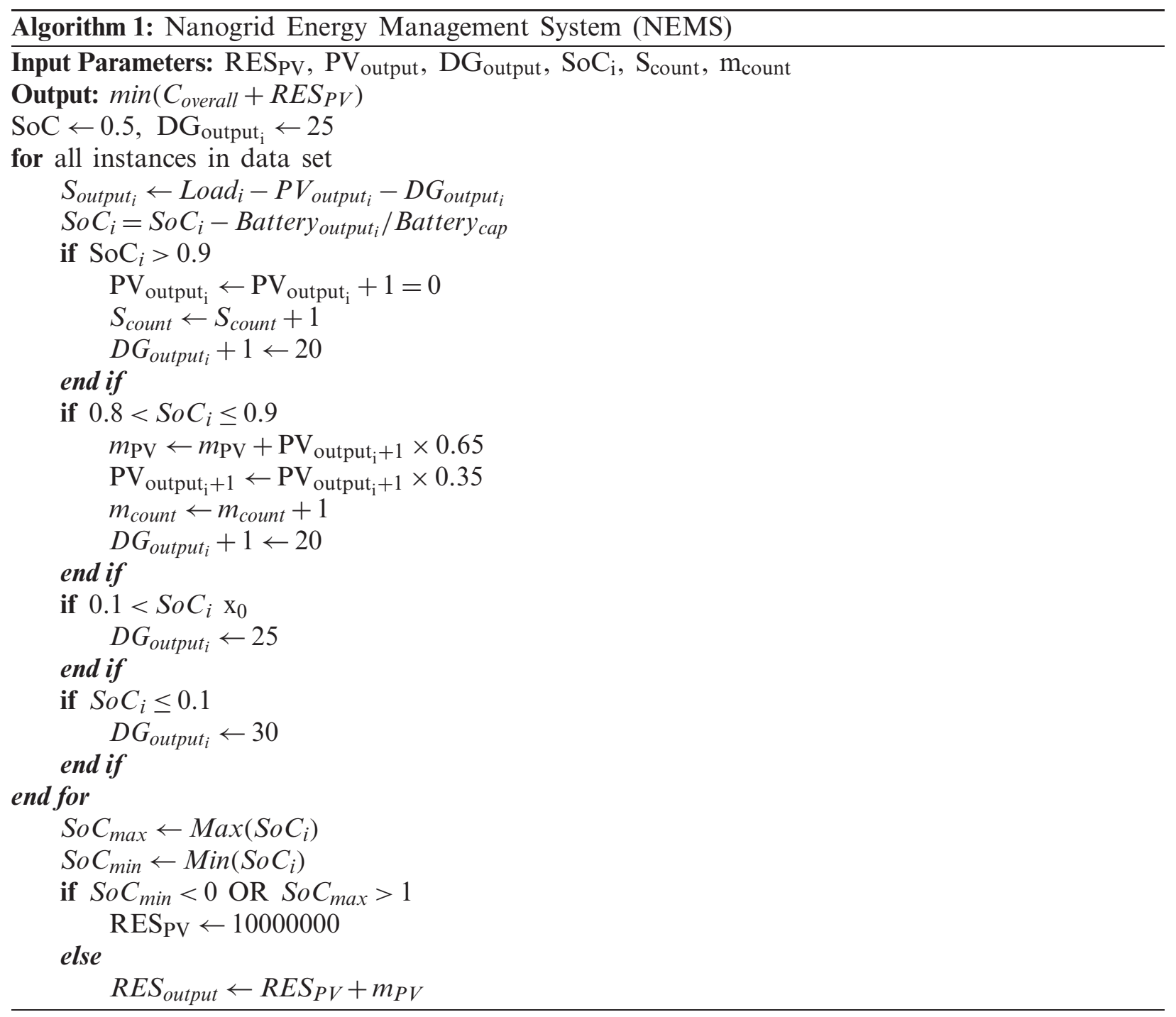

\subsection{Sequence-Modeling for Optimized Nanogrid}

This section presents an interaction model of different components of the proposed system. The sequence of the steps is given in Fig. 2 below. Initially, all modules are initialized. The configuration handler loads the configuration data and receives constraints from the constraint's handler. The configuration having some constraints, is forwarded to the next module which is input loader. The input loader loads the data and forward it to the pre-processor module. At this step, normalization is performed to normalize the data and fix anomalies via interpolation. 
The data along with the configuration data is forwarded to the optimizer. The optimizer runs PSO configuration for optimization. The results are given to the configuration handler along with the operational plan. The operational plan finalizes the optimal plan using NEMS algorithm and forwards the operational plan to the results viewer. The visualizer envisions the outcomes in the form a graph.

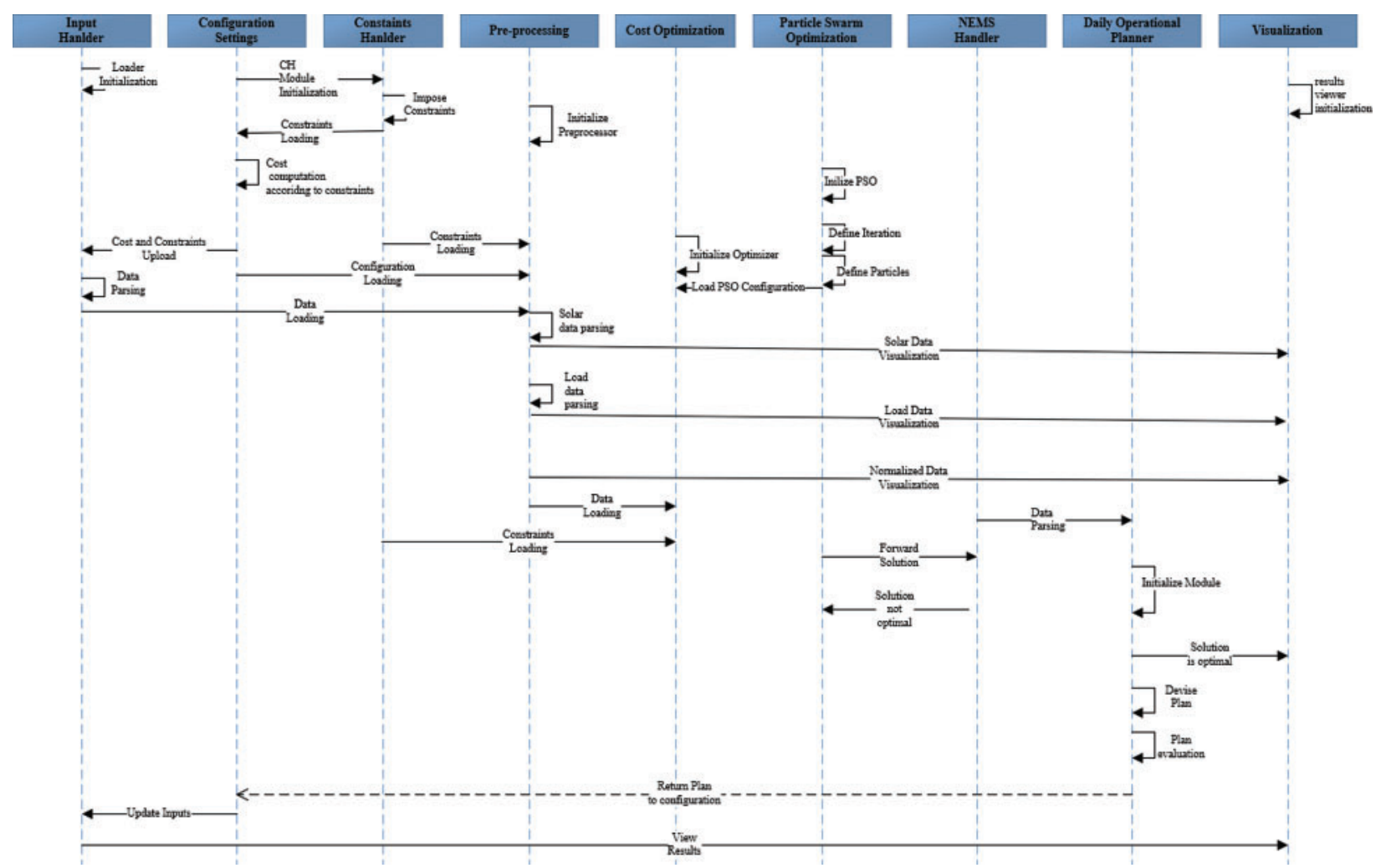

Figure 2: Sequence diagram of the proposed model

\subsection{Proposed Model Interface}

This section presents details about the interface of the proposed system. The interface has been designed using C\#. Different forms have been designed to get input data, process it, and display the results. Following is the main interface of the proposed NEMS.

The main interface has the initial data values, as illustrated in Tab. 2, and shown in Fig. 3. These values are pre-populated ones and provide idea for the business requirements of the nanogrid. These initial configurations may be amended as per requirements. The configuration form may be deemed as a placeholder that holds optimal values in the context of nanogrid. This configuration form can also act as a placeholder for optimal values. Thus, when the optimizer runs, the optimal values replace the initial values for the proper working of the nanogrid. The final values are saved to be employed in NEMS. 
Table 2: Configuration interface

\begin{tabular}{|c|c|c|c|c|c|c|}
\hline \multicolumn{7}{|l|}{ Configuration settings } \\
\hline Battery & & Min & 5 & & Max & 30 \\
\hline $\mathrm{m}$ & & Min & 0 & & Max & 30 \\
\hline Installation cost of PV & & & & 1500 & & \\
\hline $\mathrm{O}$ and $\mathrm{M}$ cost of $\mathrm{PV}$ & & & & 2 & & \\
\hline Installation cost of DG & & & & 150 & & \\
\hline $\mathrm{O}$ and $\mathrm{M}$ cost of $\mathrm{DG}$ & & & & 5 & & \\
\hline Installation cost of battery & & & & 500 & & \\
\hline $\mathrm{O}$ and $\mathrm{M}$ cost of battery & & & & 3 & & \\
\hline Price coefficient of DG & $\mathrm{x}$ & 0 & $\mathrm{y}$ & 0.2 & $\mathrm{Z}$ & $4.26 \times 10^{-3}$ \\
\hline Price coefficient of DG & $\mathrm{x}$ & $1 \times 10^{-3}$ & $\mathrm{y}$ & 0.2 & $\mathrm{z}$ & $1.6 \times 10^{-4}$ \\
\hline
\end{tabular}

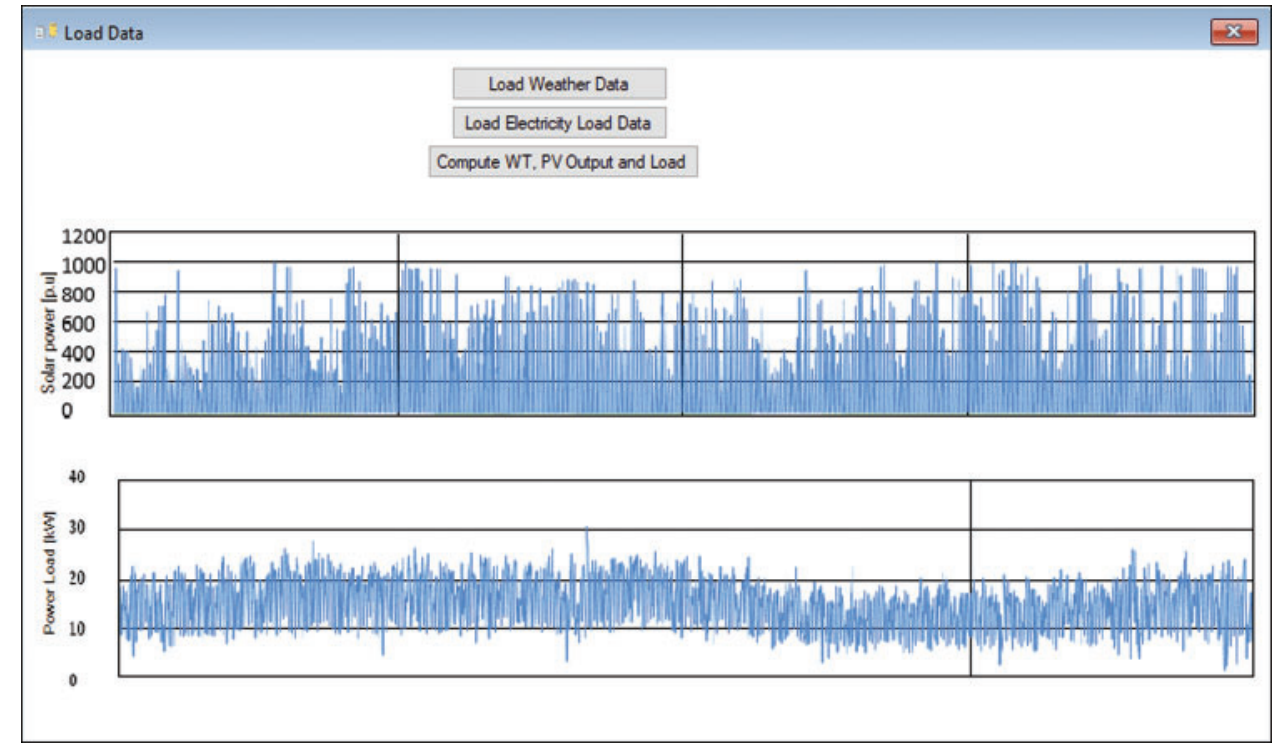

Figure 3: Interface to load data

On clicking the data button, the files containing data for weather and load demand are uploaded. In addition, the weather data includes data for solar radiation. Next, the data values are normalized and shown in line graphs, as shown in Fig. 5. The graph represents load in $\mathrm{kWh}$, and solar radiation in per unit. After that, an optimization interface is selected, providing different algorithms choices, rPSO being the core optimization algorithm.

The optimized values returned by the previous phase are given to the proposed NEMS algorithm, which is shown in Tab. 3. The interface shown in Tab. 3 appears after NEMS runs by incorporating the input values received from optimization. Tab. 3 shows comprehensive outcomes of the proposed study enlisting values for installation and operational cost. As explained earlier, the main focus has been given on the NEMS is to most utilization of renewable energy sources 
(i.e., PV) and least utilization of diesel generators. Therefore, the value for operational cost ensures the high use of renewable energy sources.

Table 3: Results showing reduced cost and optimal values

\begin{tabular}{|c|c|c|c|}
\hline \multicolumn{4}{|l|}{ Results } \\
\hline PV $23 \mathrm{~kW}$ & $25 \mathrm{kWh}$ & m0 $\quad 0.10$ p.u & 0.13 p.u \\
\hline Total generated RE & 25.20 & Diesel op. cost & 70 \\
\hline Total generated DE & 5.7 & Renewable op. cost & 68 \\
\hline Total load demand & 25 & Diesel op. cost & 70 \\
\hline Actual REP & 60.5 & Total op. cost & 140 \\
\hline Total restricted $\mathrm{RE}$ & 0.5 & Total installation cost & 5250 \\
\hline Total time restricted RE & 25 & Total $\mathrm{O}$ and $\mathrm{M}$ cost & 200 \\
\hline Original grid op. cost (only diesel) & 400 & Total cost & 1403 \\
\hline
\end{tabular}

\section{Experiments and Analysis}

Once the proposed optimization model is implemented, the next step involves its evaluation. Before applying algorithms for evaluation, we have observed the values of generated energy to meet the load demand. The observation is made on multiple iterations. It is evident from Fig. 4 that the model has produced energy whereof load demands are met fully in all iterations. Figs. 5 and 6 show the values of energy output and battery SoC for different iterations.

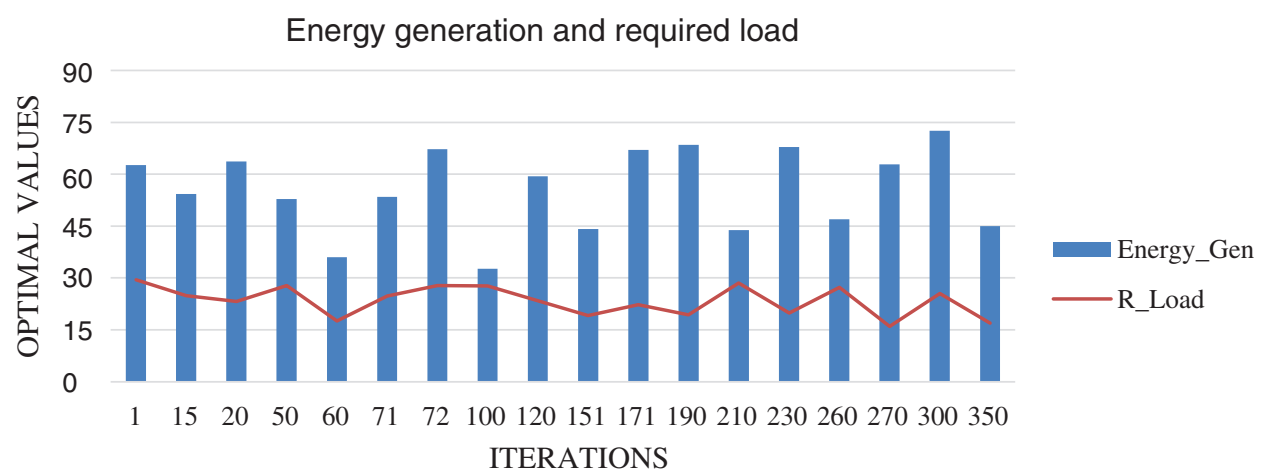

Figure 4: Optimized values to meet load requirements

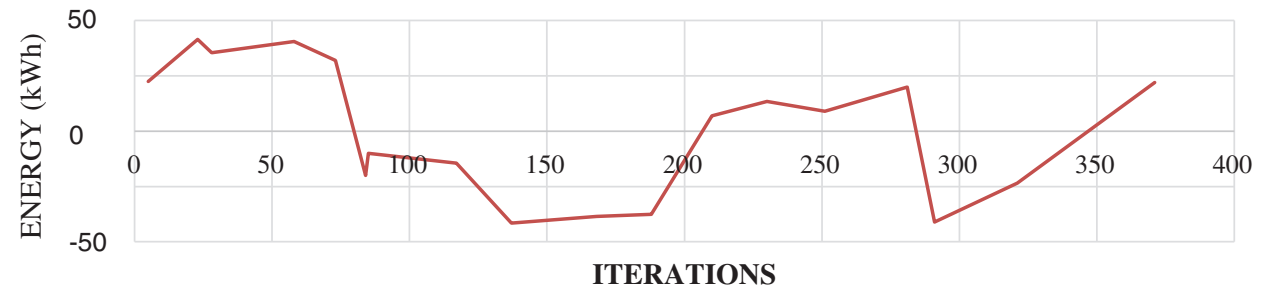

Figure 5: Energy output in different iterations 


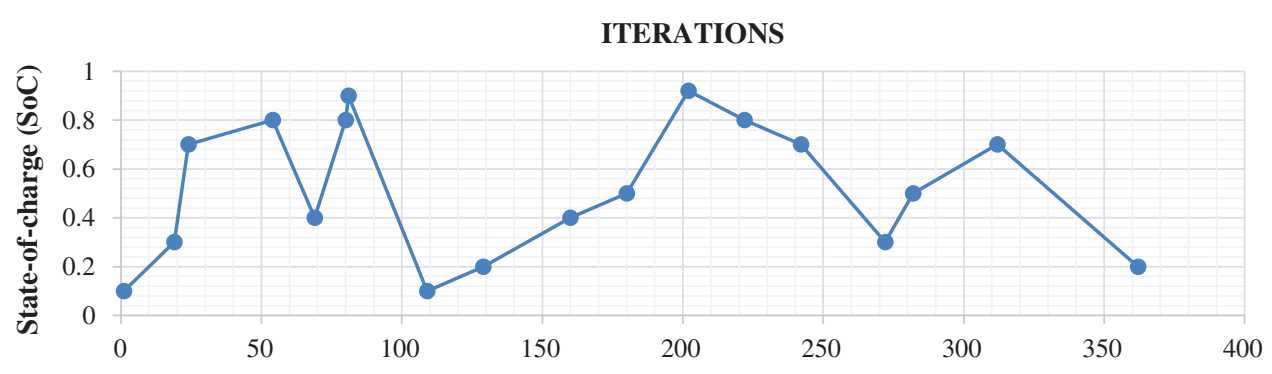

Figure 6: Battery SoC in different iterations

\subsection{Cost and Execution Time}

The proposed model has been evaluated to assess the operational cost and renewable energy penetration. The cost is further split in terms of renewable energy costs, diesel operation costs, total produced renewable energy, and generated diesel cost. The details are shown in Fig. 7a. It can be seen from the figure that rPSO has produced least cost among its counterparts (i.e. PSO, GA and BAT). The low value for cost ensures the least utilization of diesel generator. Execution time is an essential factor that must be integrated with cost to decide optimal parameters. The Fig. $7 \mathrm{~b}$ shows the execution time taken by the algorithms.

(a)

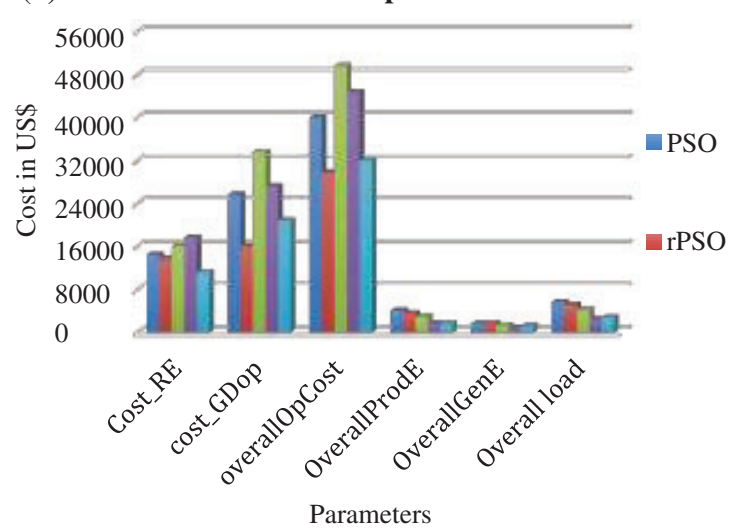

(b)

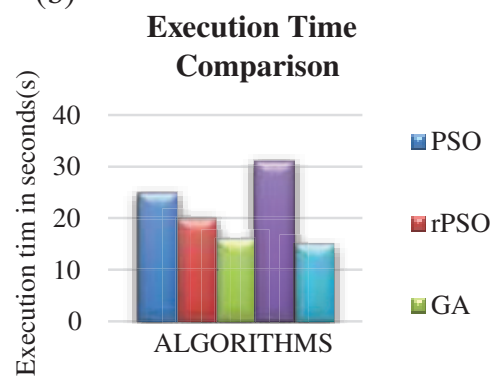

Figure 7: (a) Cost values produced by evaluation algorithms (b) Execution time taken by the algorithms

Conversely, rPSO has taken more time than PSO and GA. The less time has been reported for GA. The reported values for execution time, shown in Figure, exhibit the average consumed time obtained via multiple runs with varied parameter settings like varying number of interactions. It is evident from the figure that AMPL solvers have produced best result for time execution followed by GA, rPSO, PSO, and BAT. However, there is no significant difference in the execution time of rPSO and AMPL solvers. Considering both factors, i.e., cost and execution time, rPSO seems to be a quite balanced approach. 


\subsection{Renewable Energy Penetration}

As explained earlier, one of the primary objectives of the proposed approach is to meet the load demand of utility grids from renewable energy resources. In an ideal scenario, renewable energy penetration should be more than the required load. However, the performance of PV depends on the weather. Therefore, the optimal plan for nanogrid should be capable of meeting the load from renewable energy penetration most of the time. Maximum renewable energy penetration can be acquired by minimizing the utilization of diesel generator and maximizing utilization of PV, keeping the projected load static. The performance of renewable energy penetration is evaluated using two additional solvers IPOPT and CPLEX, as these are deemed best to address optimization problem. The obtained values are shown in Fig. 8a. IPOT and CPLEX solvers performed best among other evaluation measures, followed by GA and PSO at the end. The proposed rPSO performed better than PSO and GA and minor; therefore, it is the best solution among traditional methods. The least amount of time has been consumed by CPLEX, Minos, IPOPT followed by PSO and GA. Most of the time is consumed by rPSO. Like the execution time considered for the cost (as shown in Fig. 8b), rPSO has taken most of the time. However, considering the collective contribution of energy production and execution time, rPSO can be deemed an ideal approach. We have evaluated the performance of the proposed NEMS by considering all the possible aspects. The overall outcomes consider the rPSO as an ideal solution to reduce nanogrid total cost inclusive cost required for installation, maintenance, and operation.
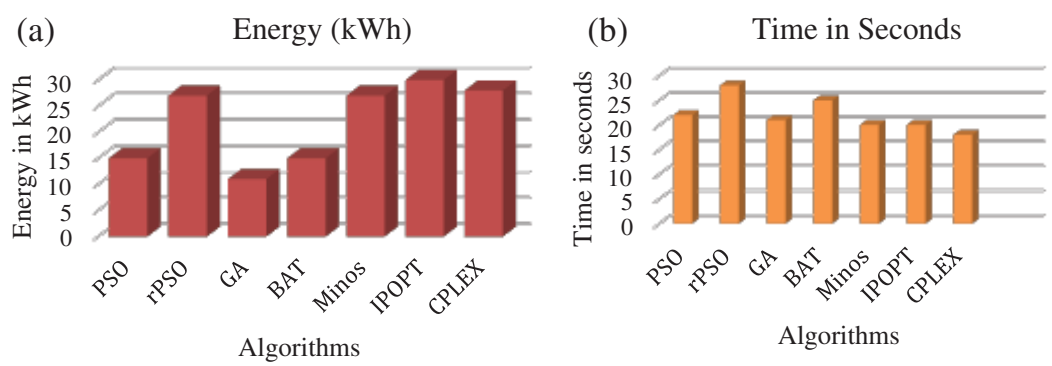

Figure 8: (a) Renewable energy penetration (b) Execution times comparison

\section{Conclusion}

Due to several inherited advantages, nanogrids have become a major source of electricity for energy consumers across the globe. In most nanogrid infrastructures, hybrid renewable energy systems (HRES) are implemented wherein renewable and non-renewable energy resources are harnessed collectively to meet the energy requirements. Based on critical analysis, we have identified that existing literature on nanogrid overlooks various vital factors while providing optimal solutions for nanogrid's cost. In this study, we have addressed the identified issues and introduced a novel Nanogrid Energy Management System (NEMS), which has maximum utilization of renewable energy sources and minimum utilization of non-renewable energy sources along with a daily operational plan in a cost-efficient manner. We have designed a novel objective function and implemented it using recursive particle swarm optimization (rPSO). The system has been evaluated using BAT, GA and AMPL solvers. The outcomes of the proposed study resulted in minimum overall cost value for nanogrid and intelligent daily operational plan. 
Acknowledgement: This study the collaboration work of "JNU and Energy Cloud R\&D Program through the National Research Foundation of Korea (NRF) funded by the Ministry of Science, ICT (2019M3F2A1073387), and this research was supported by Institute for Information \& communications Technology Planning \& Evaluation (IITP) grant funded by the Korea government (MSIT) (No. 2018-0-01456, AutoMaTa: Autonomous Management framework based on artificial intelligent Technology for adaptive and disposable IoT".

Funding Statement: The authors received no specific funding for this study.

Conflicts of Interest: The authors declare that they have no conflicts of interest to report regarding the present study.

\section{References}

[1] R. Zahedi and G. B. Gharehpetian, "Optimal sizing of floating photovoltaic system equipped with hydrogen tank and battery ESS," in IEEE Smart Grid Conf. (SGC), pp. 1-5, 2019.

[2] P. Friedlingstein and R. Houghton, G. Marland, J. Hackler, T. A. Boden et al., "Update on $\mathrm{CO}_{2}$ emissions," Nature Geoscience, vol. 3, no. 12, pp. 811-812. 2010.

[3] S. Kalambe and G. Agnihotri, "Loss minimization techniques used in distribution network: Bibliographical survey," Renewable and Sustainable Energy Reviews, vol. 29, pp. 184-200, 2014.

[4] A. M. A. Haidar, K. Muttaq and D. Sutanto, "Smart grid and its future perspectives in Australia," Renewable and Sustainable Energy Reviews, vol. 51, pp. 1375-1389, 2015.

[5] S. Uski and I. Kim, "Assessment of wind power impact on power system transmission losses," in IEEE PES Innovative Smart Grid Technologies Europe, pp. 1-5, 2014.

[6] D. Akinyele, R. Rayudu and N. Nair, "Development of photovoltaic power plant for remote residential applications: The socio-technical and economic perspectives," Applied Energy, vol. 155, pp. 131-149, 2015.

[7] H. Holtorf, T. Urmee, M. Calais and T. Pryor, "A model to evaluate the success of solar home systems," Renewable and Sustainable Energy Reviews, vol. 50, pp. 245-255, 2015.

[8] C. Rae and F. Bradley, "Energy autonomy in sustainable communities a review of key issues," Renewable and Sustainable Energy Reviews, vol. 16, no. 9, pp. 6497-6506, 2012.

[9] P. Descateaux, M. F. Astudillo and B. Amor, "Assessing the life cycle environmental benefits of renewable distributed generation in a context of carbon taxes: The case of the northeastern American market," Renewable and Sustainable Energy Reviews, vol. 53, pp. 1178-1189, 2016.

[10] D. Burmester, R. Rayudu, W. Seah and D. Akinyele, "A review of nanogrid topologies and technologies," Renewable and Sustainable Energy Reviews, vol. 67, pp. 760-775, 2017.

[11] R. Ayop, N. M. Isa and C. W. Tan, "Components sizing of photovoltaic stand-alone system based on loss of power supply probability," Renewable and Sustainable Energy Reviews, vol. 81, pp. 2731-2743, 2018.

[12] M. Ban, M. Shahidehpour, J. Yu and Z. Li, "A cyber-physical energy management system for optimal sizing and operation of networked nanogrids with battery swapping stations," IEEE Transactions on Sustainable Energy, vol. 10, no. 1, pp. 491-502, 2017.

[13] I. Strnad and R. Prenc, "Optimal sizing of renewable sources and energy storage in low-carbon microgrid nodes," Electrical Engineering, vol. 100, no. 3, pp. 1661-1674, 2018.

[14] U. Akram, M. Khalid and S. Shafiq, "An improved optimal sizing methodology for future autonomous residential smart power systems," IEEE Access, vol. 6, pp. 5986-6000, 2018.

[15] M. Lee, T. Hong, K. Jeong and J. Kim, "A bottom-up approach for estimating the economic potential of the rooftop solar photovoltaic system considering the spatial and temporal diversity," Applied Energy, vol. 232, pp. 640-656, 2018.

[16] I. Firtina-Ertis, C. Acar and E. Erturk, "Optimal sizing design of an isolated stand-alone hybrid windhydrogen system for a zero-energy house," Applied Energy, vol. 274, pp. 115244, 2020. 
[17] A. Brocco, "Fully distributed power routing for an ad hoc nanogrid"” in 2013 IEEE Int. Workshop on Inteligent Energy Systems (IWIES) IEEE, Vienna, Austria, pp. 113-118, 2013.

[18] M. Biabani, M. A. Golkar, A. Johar and M. Johar, "Propose a home demand-side-management algorithm for smart nano-grid," in 4th Annual Int. Power Electronics, Drive Systems and Technologies Conf., Tehran, Iran, IEEE, February, pp. 487-494, 2013.

[19] S. Mansour, G. Joós, I. Harrabi and M. Maier, "Co-simulation of real-time decentralized vehicle/grid (RT-dVG) coordination scheme for e-mobility within nanogrids," in 2013 IEEE Electrical Power \& Energy Conf., Halifax, NS, Canada, IEEE, pp. 1-6, 2013.

[20] T. Logenthiran, D. Srinivasan and T. Z. Shun, "Demand side management in smart grid using heuristic optimization," IEEE Transactions on Smart Grid, vol. 3, no. 3, pp. 1244-1252, 2012.

[21] S. Barker, A. Mishra, D. Irwin and P. Shenoy, "Smartcap: Flattening peak electricity demand in smart homes," in 2012 IEEE Int. Conf. on Pervasive Computing and Communications IEEE, pp. 67-75, 2012.

[22] R. Adda, O. Ray, S. K. Mishra and A. Joshi, "Synchronous-reference-frame-based control of switched boost inverter for standalone DC nanogrid applications," IEEE Transactions on Power Electronics, vol. 28, no. 3, pp. 1219-1233, 2012.

[23] A. Goikoetxea, J. M. Canales, R. Sanchez and P. Zumeta, "DC versus AC in residential buildings: Efficiency comparison," in Eurocon 2013 IEEE, Zagreb, Croatia, pp. 1-5, 2013.

[24] S. Poshtkouhi, M. Fard, H. Hussein and L. M. D. Santos, "A dual-active-bridge based bi-directional micro-inverter with integrated short-term li-ion ultra-capacitor storage and active power smoothing for modular pv systems," in 2014 IEEE Applied Power Electronics Conf. and Exposition-APEC 2014 IEEE, Fort Worth, TX, USA, pp. 643-649, 2014.

[25] O. Ray and S. Mishra, "Boost-derived hybrid converter with simultaneous DC and AC outputs," IEEE Transactions on Industry Applications, vol. 50, no. 2, pp. 1082-1093, 2013.

[26] H. Keyhani and H. A. Toliyat, "Single-stage multistring PV inverter with an isolated high-frequency link and soft-switching operation," IEEE Transactions on Power Electronics, vol. 29, no. 8, pp. 39193929, 2013.

[27] S. Kumar, V. Krishnasamy, R. Kaur and N. K. Kandasamy, "Virtual energy storage-based energy management algorithm for optimally sized DC nanogrid," IEEE Systems Journal, pp. 1-9, 2021.

[28] A. T. Dahiru, C. W. Tan, A. L. Bukar and K. Y. Lau, "Energy cost reduction in residential nanogrid under constraints of renewable energy, customer demand fitness and binary battery operations," Journal of Energy Storage, vol. 39, pp. 102520, 2020. 